\title{
The Mechanism of Sympathovagal Imbalance in Patients with Myocardial Ischemia
}

\author{
Chuen-Den Tseng, MD, Tzong-Luen WANG, MD, \\ Jiunn-Lee LIN, MD, Kwan-Lih Hsu, MD, \\ Fu-Tien Chiang, MD, Wen-Pin Lien, MD, \\ and Yung-Zu Tseng, MD
}

\section{SUMMARY}

To investigate the mechanism of sympathovagal imbalance due to myocardial ischemia, we studied 42 consecutive patients undergoing successful percutaneous transluminal coronary angioplasty by correlating frequency domain and time domain measures of heart rate variability with parameters such as echocardiography, stress thallium scanning and radionuclide angiography before, immediately after and 2 months after the procedure. Of these, 20 patients (Group N) had normal and 22 patients (Group A) had abnormal regional wall motion. A control group of 20 healthy subjects (Group C) underwent echocardiography and examination of heart rate variability twice at 2-month intervals to check for spontaneous variations. At baseline, frequency domain measures such as low and high frequency power and time domain measures such as SDANN index (the mean of the standard deviations of the average of RR intervals) were lower in Group A than in Groups $\mathrm{N}$ and $\mathrm{C}$, whereas no differences were detectable in ultra low and very low frequency, total power, SDNN index (the mean of the standard deviations of the mean of normal RR intervals), and r-MSSD (the root mean square of successive RR differences). There was high association between the diastolic wall stress index and both high frequency $(r=-0.82)$ and low frequency power $(r=-0.77)$. There were similar findings for the systolic wall stress index $(r=-0.72$ for high frequency and $r=-0.64$ for low frequency power). After successful coronary angioplasty, regional wall motion, left ventricular wall stress indices and all measures of heart rate variability were unchanged in Group N. In Group A the mean summed segment score improved from $15.9 \pm 2.6$ to $12.2 \pm 1.7(p<0.0001)$, and mean low frequency, mean high frequency power (logarithmic units), and SDANN index (msec) increased from $6.10 \pm 0.23$ to $6.36 \pm 0.28(p<0.005)$, from $5.36 \pm 0.40$ to $5.70 \pm 0.39(p<0.01)$ and from $70 \pm 18$ to $83 \pm 18$ $(p<0.01)$ respectively. In addition, low and high frequency power and SDANN index, lower at baseline in Group A than in the other two groups,

\footnotetext{
From Department of Internal Medicine, National Taiwan University Hospital, Taipei, Taiwan, Republic of China.

Address for correspondence: Chuen-Den Tseng, MD, Department of Internal Medicine, National Taiwan

University Hospital, 7 Chung-Shan South Road, Taipei, Taiwan, Republic of China.

Received for publication June 28, 1995.

Accepted October 4, 1995.
} 
were comparable in the three groups after coronary angioplasty. The evolution of diastolic and systolic wall stress indices paralleled that of the above three parameters. In conclusion, diastolic and systolic wall stress indices, in addition to segmental left ventricular dysfunction, were synergistically involved in determining sympathovagal imbalance in patients with significant coronary artery disease; the reversal of left ventricular dysfunction and wall stress indices improves the profile of heart rate variability. Alterations in cardiac geometry and wall stress influence mainly the discharge of afferent sympathetic and efferent parasympathetic innervations and also principally the long-term heart rate variations instead of short-term modulation. (Jpn Heart J 1996; 37: 43-58)

Key words: Heart rate variability Coronary artery disease Left ventricular wall stress Regional wall motion abnormality

$7 \mathrm{O}$ our knowledge, cardiac sensory endings can be activated in myocardial ischemia. ${ }^{1-3)}$ Sympathovagal imbalance has also been reported to occur via a similar mechanism after acute myocardial infarction. ${ }^{48)}$ Heart rate variability, which is one of the most popular methods to study sympathovagal activity, is therefore used for risk stratification of post-infarct complications..$^{-11}$ )

Imbalance in autonomic control of heart rate has been reported in patients with chronic stable angina ${ }^{12-14)}$ whereas decline of vagal tone during electrocardiographic ST segment depression was also suggested as a possible mechanism of ischemic arrhythmia. ${ }^{15)}$ Although alterations in cardiac geometry that influence the discharge of afferent sympathetic mechanoreceptors were proposed as a mechanism of the derangement in autonomic control of heart rate in the patients with one-vessel coronary artery disease, ${ }^{16)}$ it is still uncertain whether this simple mechanism can account for sympathovagal imbalance in ischemic heart disease.

To investigate the mechanism of sympathovagal imbalance in cases with myocardial ischemia, we assessed the evolution of frequency and time domain measures of heart rate variability in patients who underwent successful percutaneous transluminal coronary angioplasty. Various parameters of concomitant echocardiograms, stress thallium scan, radionuclide angiography and catheterizations were also recorded for analysis of possible mechanisms.

\section{Methods}

Patients and study protocol: One hundred patients with significant coronary artery disease who underwent successful coronary angioplasty between June 1993 and July 1994 were considered for the study. Patients were excluded if they had a history of 1) myocardial infarction within 1 year, 2) moderate to severe hypertension, 3) diabetes; 4) congestive heart failure; or 5) significant valvular heart disease. Finally, 42 patients ( 34 men, 8 women; mean $[ \pm S D]$ age $57.4 \pm 10.2$ 
years) were enrolled. Each patient signed a written informed consent form approved by the Ethical Committee of our institution.

Holter monitoring for heart rate variability analysis, two-dimensional echocardiography, radionuclide angiography and stress thallium scanning were performed in hospital 24 hours before coronary angioplasty and were repeated 24 hours and 2 months after the procedure. Cardiac catheterizations were performed $\leq 2$ days (median 0 days) before angioplasty, immediately after and 2 months after angioplasty.

Twenty age-matched healthy subjects ( 16 men, 4 women; mean 59 years, range 42 to 68 ), selected from the potential candidates admitted to the hospital for evaluation of chest pain, formed the control group (Group C). Detailed history, physical examination, chest radiographs, echocardiograms and supine and standing blood pressures were recorded. If any evidence of disease was found, the subject was excluded. In these subjects 24-hour Holter monitoring was performed twice at 2 month intervals to check for spontaneous variations of heart rate variability. Recordings were obtained first in hospital and second in the outpatient setting, as in the study patients.

Drug adminstration: All patients were treated with a calcium blocking agent, usually diltiazem, 30 to $60 \mathrm{mg}$ three times a day, and with long-acting nitrates and aspirin at the time of first evaluation and during follow-up. No other medicine which could potentially affect sympathovagal activities was used if possible. Echocardiography: Patients were studied in the left lateral decubitus position using parasternal, apical and subcostal views with a 2.5 or $3.5 \mathrm{MHz}$ transducer applied to a commercially available apparatus (Toshiba SSD-226, Tokyo, Japan). Wall motion was evaluated in 11 segments of a left ventricular model derived from that proposed by Edwards et al. ${ }^{17}$ ) Studies were considered adequate for analysis only when each of these 11 segments was included in at least one view. Wall motion in each segment was graded on a scale of 1 to $4(1=$ normal, $2=$ hypokinetic, $3=$ akinetic, $4=$ dyskinetic), ${ }^{18)}$ and a summed segment score was calculated by summing the score for each segment.

In addition, left ventricular diastolic and systolic wall stress indices were calculated according to the following formulae ${ }^{19)}$ : diastolic wall stress index $\left(\right.$ dynes $\left./ \mathrm{cm}^{2}\right)=333 \times$ LVEDP $\times$ LVIDd / [PWTd $(1+$ PWTd / LVIDd)]; systolic wall stress index $\left(\right.$ dynes $\left./ \mathrm{cm}^{2}\right)=333 \times \mathrm{SBP} \times \mathrm{LVIDs} /\left[\mathrm{PWT}_{\mathrm{s}}(1+\mathrm{PWTs} /\right.$ LVIDs)] where SBP = systolic blood pressure $(\mathrm{mm} \mathrm{Hg}) ; \mathrm{LVIDs}=$ left ventricular internal dimension at end-systole $(\mathrm{cm})$; LVIDd $=$ left ventricular internal dimension at end-diastole; PWTs = posterior wall thickness during systole $(\mathrm{cm}) ;$ PWTd = posterior wall thickness during diastole $(\mathrm{cm})$; and LVEDP = left ventricular diastolic pressure. The LVEDP was measured by cardiac catheterization which was performed less than 24 hours before echocardiography for consecutive pa- 
tients and was assumed to be $10 \mathrm{mmHg}$ in the control group. The systolic arterial pressure was represented by the cuff sphygmomanometer measurement. The difference between the systolic arterial pressure measured by the sphygmomanometer and the systolic pressure at the ascending aorta measured by cardiac catheterization was $4 \pm 2 \%$ in our study.

The examinations, stored on videotape, were reviewed and analyzed by two observers independently. Concordance of analysis was achieved in 95\% of cases; in the remaining $5 \%$ the studies were reviewed and agreement obtained.

Radionuclide angiography: Stress thallium scanning was performed according to an established method with the Bruce protocol. ${ }^{20,21)}$ As the patient reaches the target level of exercise, 1.5 to $2.0 \mathrm{mCi}$ of ${ }^{201} \mathrm{Tl}$ was injected through a previously established intravenous line. The patient continued to exercise for 45 to 90 seconds to permit a high level of myocardial extraction of ${ }^{201} \mathrm{Tl}$ under exercise conditions. Imaging was started within 5 or 10 minutes following cessation of exercise before substantial redistribution of myocardial ${ }^{201} \mathrm{Tl}$ could occur. Imaging was ordinarily repeated 4 hours following exercise in order to identify regions of thallium redistribution. Long-axis, short-axis and coronal tomograms were analysed for detecting regional myocardial hypoperfusion.

Radionuclide ventriculography was performed with an established in vivo gated blood pool method ${ }^{22)}$ and the Bruce protocol. ${ }^{99 \mathrm{~m}} \mathrm{Tc}$-pertechnetate $(15 \mu \mathrm{g} /$ $\mathrm{Kg}$ body weight) was used as the radionuclide for labelling red blood cells. A small field-of-view Anger gamma camera with crystal thickness of $0.63 \mathrm{~cm}$ or $0.95 \mathrm{~cm}$ was used for cardiac pool imaging. Anterior, left anterior oblique, and left lateral vicws wcre routincly analysed for detecting regional wall motion abnormalities.

Processing of 24-hour Holter ECG Monitoring: All 24-hour Holter ECG recordings were collected by the Delmar Avionics electroscanner at the Electrophysiology Laboratory of our institution. The two-channel ECG analog signal was played back at 60 times the recording speed, and was sampled at $200 \mathrm{~Hz}$. In addition to evaluation of the usual ECG variables, including identification of $Q R S$ widths and shapes and $R R$ interval abnormalities, the sequences of all $R R$ intervals were stored, and each RR interval was labeled with a code number identifying its normality or class of abnormality. The computer program automatically detects and labels each QRS complex and filters out the RR intervals that differ in duration by $>30 \%$ from the previously accepted intervals. A physician would make a final check to detect falsely labeled RR intervals and artifacts. Patients with persistent rhythm anomalies and tapes with excessive artifacts were excluded. The sequence of normal $\mathrm{RR}$ intervals $(\mathrm{NN})$, after exclusion of each abnormal interval and of the two before and after it, used only for timekeeping purposes, was analyzed to compute frequency domain measures of heart rate 
variability.

The following time domain indices of heart rate variability were determined: ${ }^{23-29)}$ (1) r-MSSD = root-mean-square of successive differences in normal RR (NN) intervals among consecutive normal beats; (2) SDNN index = the mean of the standard deviations of all NN intervals for all 5-minute segments; (3) SDANN index = the standard deviation of the average $\mathrm{NN}$ intervals of all 5minute segments. In the frequency domain, we determined: (1) total frequency power $=$ the total power from 0.0033 to $0.40 \mathrm{~Hz}$ expressed in milliseconds squared; (2) high-frequency power = the total power from 0.15 to $0.40 \mathrm{~Hz}$; (3) low-frequency power $=$ the total power from 0.04 to $0.15 \mathrm{~Hz}$; (4) very-low frequency power $=$ the total power from 0.0033 to $0.04 \mathrm{~Hz}$; The power spectra were calculated (after correction for ectopy and noise by deletion and substitution of the subsequent $\mathrm{NN}$ interval) as the average of all nonoverlapping 5 minute power spectra using a 1024-point fast Fourier transform. Power spectral analysis of heart rate variability refers to the determination of the specific frequencics at which variations in heart ratc occur. The tcchnique yields a curve describing the amplitudes of the individual frequency components of a patient's heart rate variability. The amplitude of the oscillation, or "power", which is amplitude squared, at any given frequency and the total contribution to heart rate variability contained within a range of frequencies can then be analyzed.

Because the distribution of the frequency domain measures of heart period variability are extremely skewed, the $\log$ transformation ( $\mathrm{Ln}$ ) of each measure (which produces nearly normal distribution) was applied before statistical analysis was performed.

Cardiac catheterization, coronary angiography and angioplasty: Rightsided catheterization including pressure tracings and oxygen saturation at each cardiac chamber were recorded according to well-established methods. ${ }^{30}$ Coronary angiography was performed before the angioplasty in $\geq 3$ projections, with cranial and/or caudal angulated views. The view with the best visualization of the lesion was selected and the severity of the stenosis diameter program included in the Philips DCI S system. Severity of all coronary lesions was determined by visual assessment with the consensus of two experienced angiographers. The presence of collateral flow was graded as proposed by Cohen and Rentrop ${ }^{31 \text { : }}$ : $0=$ no visible collaterals; $1=$ visible intraseptal collateral channels; $2=$ partial filling of a segment of the left anterior descending artery or the main side branches; and $3=$ complete filling of the artery and its side branches. Left ventricular ejection fraction was calculated in the $30^{\circ}$ right anterior oblique projection using the area-length method. ${ }^{31}$ All coronary lesions $>70 \%$ narrowing or the stenosis of left main coronary artery $>50 \%$ was considered significant. Gensini scores and coronary artery disease prognosis indices were also calculated accord- 
ing to the established method to assess the severity of the coronary artery disease. $^{32,33)}$

Statistical analysis: Categoric variables were expressed as percent and compared using the chi-square test. Continuous data are expressed as mean value \pm $\mathrm{SD}$ and were analyzed using one-way analysis of variance; if a significant $(p<0.05) \mathrm{F}$ test was found, the Student $t$ test for unpaired observations with the Bonferroni correction was used for multiple comparison; a paired $t$ test was performed to evaluate data obtained in the same group. A simple linear regression model was also used for evaluating the correlation coefficient between different clinical data and parameters of heart rate variability. If a $p<0.05$ could be reached in the univariate analysis, the related variable would be enrolled into the multivariate analysis. Statistical significance was defined as $p<0.05$.

\section{Results}

Relationship between echographically regional left ventricular dysfunction

Table I. Clinical Characteristics of Patients with Normal Segmental Left Ventricular Wall Motion (Group N)

\begin{tabular}{|c|c|c|c|c|c|c|c|}
\hline Patient No. & $\begin{array}{l}\text { Age }(y r) / \\
\text { gender }\end{array}$ & $\begin{array}{l}\text { Previous } \\
\text { infarct } \\
\text { location }\end{array}$ & $\mathrm{EF}(\%)$ & $\begin{array}{l}\text { Vessel } \\
\text { dilated }\end{array}$ & $\begin{array}{l}\text { Gensini } \\
\text { score }\end{array}$ & $\begin{array}{l}\text { Coronary artery } \\
\text { disease prognosis } \\
\text { index }\end{array}$ & $\begin{array}{c}\text { Summed score } \\
\text { (Before/after } \\
\text { PTCA) }\end{array}$ \\
\hline \multicolumn{8}{|l|}{ Previous MI } \\
\hline 1 & $58 / \mathrm{M}$ & IWMI & 61 & LCx & 5 & 23 & $11 / 11$ \\
\hline 2 & $60 / F$ & IWMI & 58 & LAD, RCA & 6 & 42 & $11 / 11$ \\
\hline 3 & $52 / \mathrm{M}$ & NQWMI & 59 & LAD & 7 & 42 & $11 / 11$ \\
\hline 4 & $65 / \mathrm{M}$ & AWMI & 50 & $\mathrm{LAD}, \mathrm{LCx}$ & 10 & 48 & $11 / 11$ \\
\hline 5 & $44 / \mathrm{M}$ & IWMI & 62 & $\mathrm{LCx}$ & 10 & 23 & $11 / 11$ \\
\hline 6 & $67 / \mathrm{M}$ & IWMI & 56 & RCA & 8 & 23 & $11 / 11$ \\
\hline \multicolumn{8}{|c|}{ No previous MI } \\
\hline 7 & $56 / \mathrm{M}$ & & 68 & $\mathrm{LAD}$ & 5 & 42 & $11 / 11$ \\
\hline 8 & $54 / \mathrm{M}$ & & 511 & LAD, LCX, RGA & 12 & 63 & $11 / 11$ \\
\hline 9 & $62 / \mathbf{F}$ & & 53 & LAD, RCA & 7 & 48 & $11 / 11$ \\
\hline 10 & $49 / \mathrm{M}$ & & 72 & LCx & 8 & 23 & $11 / 11$ \\
\hline 11 & $68 / \mathrm{M}$ & & 69 & RCA & 5 & 23 & $11 / 11$ \\
\hline 12 & $45 / \mathrm{M}$ & & 67 & LAD, RCA & 12 & 48 & $11 / 11$ \\
\hline 13 & $57 / \mathrm{F}$ & & 50 & $\mathrm{LAD}$ & 12 & 32 & $11 / 11$ \\
\hline 14 & $53 / \mathrm{M}$ & & 52 & LAD, LCx, RCA & 15 & 67 & $11 / 11$ \\
\hline 15 & $56 / \mathrm{M}$ & & 64 & $\mathrm{LCx}, \mathrm{RCA}$ & 11 & 37 & $11 / 11$ \\
\hline 16 & $55 / \mathrm{M}$ & & 58 & LAD & 4 & 32 & $11 / 11$ \\
\hline 17 & $61 / \mathrm{M}$ & & 71 & $\mathrm{LAD}, \mathrm{LCx}$ & 7 & 48 & $11 / 11$ \\
\hline 18 & $59 / \mathrm{M}$ & & 61 & $\mathrm{LAD}$ & 10 & 32 & $11 / 11$ \\
\hline 19 & $53 / \mathrm{M}$ & & 63 & LAD & 8 & 32 & $11 / 11$ \\
\hline 20 & $61 / \mathbf{F}$ & & 59 & LAD, RCA & 8 & 48 & $11 / 11$ \\
\hline
\end{tabular}

AWMI = anterior wall myocardial infarction; $\mathrm{EF}=$ ejection fraction; $\mathrm{IWMI}=$ inferior wall infarction; $\mathrm{LAD}=$ left anterior descending artery; $\mathrm{LCx}=$ left circumflex artery; $N Q W M I=$ non- $Q$ wave myocardial infarction; $\mathbf{R C A}=$ right coronary artery. 
and heart rate variability (Tables I, II, and III): Of 42 consecutive patients, we found 20 patients without echocardiographically regional wall motion abnormalities (Group N, Table I) and 22 with regional wall abnormalities (Group A, Table II). Age and gender were comparable among the two groups and Group C. History of previous myocardial infarction was present in $30 \%$ of patients in Group $\mathrm{N}$ and $64 \%$ of patients in Group A. Left ventricular ejection fraction was lower in Group A $(54.8 \pm 6.4 \%)$ than in Group $N(60.2 \pm 6.9 \%, p<0.05)$ and Group C $(62.7 \pm 5.8 \%, p<0.0001)$. Gensini score was higher in Group A $(12 \pm 7)$ than in Group $N(8 \pm 3, p<0.05)$. Coronary artery disease prognosis index was also higher in Group A $(47 \pm 13)$ than in Group $N(39 \pm 12, p<0.05)$.

With regard to heart rate variability measurement (logarithmic units) (Table III), there was no difference in low and high frequency power between Group $\mathrm{N}$ and Group C. Low frequency power was lower in Group A $6.10 \pm 0.23)$ than in Group N (6.38 $\pm 0.28, p<0.0001)$ and Group C $(6.37 \pm 0.26, p<0.0001)$. High

Table II. Clinical Characteristics of Patients with Abnormal Segmental Left Ventricular Wall Motion (Group A)

\begin{tabular}{|c|c|c|c|c|c|c|c|}
\hline Patient No. & $\begin{array}{l}\text { Age (yr)/ } \\
\text { gender }\end{array}$ & $\begin{array}{l}\text { Previous } \\
\text { infarct } \\
\text { location }\end{array}$ & $\mathrm{EF} / \%$ & $\begin{array}{l}\text { Vessel } \\
\text { dilated }\end{array}$ & $\begin{array}{c}\text { Gensini } \\
\text { score }\end{array}$ & $\begin{array}{l}\text { Coronary artery } \\
\text { disease prognosis } \\
\text { index }\end{array}$ & $\begin{array}{l}\text { Summed score* } \\
\text { (Before/after } \\
\text { PTCA) }\end{array}$ \\
\hline \multicolumn{8}{|l|}{ Previous MI } \\
\hline 1 & $57 / \mathrm{M}$ & AWMI & 50 & LAD & 5 & 48 & $15 / 11$ \\
\hline 2 & $62 / \mathrm{M}$ & IWMI & 48 & LCx & 7 & 32 & $14 / 11$ \\
\hline 3 & $53 / \mathrm{M}$ & AWMI & 54 & LAD, LCx, RCA & 30 & 67 & $22 / 16$ \\
\hline 4 & $56 / F$ & AWMI & 55 & LAD, LCx & 12 & 48 & $17 / 13$ \\
\hline 5 & $50 / \mathrm{M}$ & NQWMI & 58 & $\mathrm{LAD}$ & 12 & 42 & $15 / 12$ \\
\hline 6 & $46 / \mathrm{M}$ & NQWMI & 60 & LCx & 5 & 32 & $13 / 11$ \\
\hline 7 & $68 / \mathrm{M}$ & IWMI & 53 & $\mathrm{RCA}$ & 4 & 32 & $14 / 11$ \\
\hline 8 & $62 / \mathrm{F}$ & AWMI & 48 & LAD, RCA & 16 & 56 & $18 / 14$ \\
\hline 9 & $57 / \mathrm{M}$ & IWMI & 64 & $\mathrm{RCA}$ & 9 & 32 & $14 / 12$ \\
\hline 10 & $55 / \mathrm{M}$ & AWMI & 50 & LAD & 15 & 48 & $15 / 12$ \\
\hline 11 & $60 / M$ & AWMI & 52 & $\mathrm{LAD}, \mathrm{LCx}$ & 15 & 56 & $19 / 13$ \\
\hline 12 & $62 / \mathrm{M}$ & IWMI & 56 & LCx, RCA & 10 & 56 & $16 / 11$ \\
\hline 13 & $54 / \mathrm{M}$ & NQWMI & 60 & LCx & 5 & 32 & $14 / 11$ \\
\hline 14 & $58 / \mathrm{M}$ & NQWMI & 59 & LAD, RCA & 6 & 48 & $20 / 14$ \\
\hline \multicolumn{8}{|c|}{ No Previous MI } \\
\hline 15 & $56 / \mathrm{M}$ & & 49 & LAD, LCx, RCA & 28 & 74 & $21 / 17$ \\
\hline 16 & $69 / F$ & & 50 & LAD, RCA & 12 & 48 & $13 / 11$ \\
\hline 17 & $48 / \mathrm{M}$ & & 52 & $\mathrm{LAD}, \mathrm{LCx}$ & 10 & 37 & $15 / 11$ \\
\hline 18 & $54 / \mathrm{M}$ & & 54 & LCx & 10 & 32 & $14 / 11$ \\
\hline 19 & $59 / \mathrm{M}$ & & 55 & LCx, RCA & 13 & 48 & $15 / 12$ \\
\hline 20 & $60 / \mathrm{M}$ & & 53 & LAD, RCA & 8 & 48 & $15 / 11$ \\
\hline 21 & $52 / \mathrm{M}$ & & 61 & LAD, LCx, RCA & 31 & 74 & $17 / 13$ \\
\hline 22 & $59 / \mathrm{F}$ & & 47 & $\mathrm{LAD}$ & 12 & 48 & $14 / 11$ \\
\hline
\end{tabular}

$A W M I=$ anterior wall myocardial infarction; $E F=$ ejection fraction; IWMI = inferior wall infarction; $\mathrm{LAD}=$ left anterior descending artery; $\mathrm{LCx}=$ left circumflex artery; $\mathrm{NQWMI}=$ non- $\mathrm{Q}$ wave myocardial infarction; RCA = right coronary artery. *The mean summed score before and after PTCA were $15.9 \pm 2.6 \mathrm{vs}$ $12.2 \pm 1.7(p<0.0001)$. 
Table III. Heart Rate Variability before and after Coronary Angioplasty in Groups $\mathrm{N}$ and $\mathrm{A}$ and in Control Subjects (Group C)

\begin{tabular}{|c|c|c|c|}
\hline & \multicolumn{3}{|c|}{ Group N } \\
\hline & $\begin{array}{l}\text { Before } \\
\text { PTCA }\end{array}$ & $\begin{array}{l}\text { After } \\
\text { PTCA }\end{array}$ & $p$ Value \\
\hline \multicolumn{4}{|l|}{ Frequency Domain } \\
\hline Ln total power & $9.60(0.39)$ & $9.62(0.34)$ & NS \\
\hline Ln ULF power & $9.36(0.43)$ & $9.38(0.40)$ & NS \\
\hline Ln VLF power & $7.18(0.32)$ & $7.22(0.30)$ & NS \\
\hline Ln LF power & $6.38(0.28)$ & $6.37(0.27)$ & NS \\
\hline Ln HF power & $5.71(0.38)$ & $5.69(0.43)$ & NS \\
\hline \multicolumn{4}{|l|}{ Time Domain } \\
\hline $\mathrm{SDNN}$ (ms) & $90 \quad(29)$ & $92 \quad(30)$ & NS \\
\hline SDNN index (ms) & $46 \quad(13)$ & $48 \quad(14)$ & NS \\
\hline SDANN index (ms) & $80 \quad(18)$ & $84 \quad(20)$ & NS \\
\hline \multirow[t]{3}{*}{$\mathrm{r}-\mathrm{MSSD}(\mathrm{ms})$} & $22 \quad(14)$ & $23 \quad(15)$ & NS \\
\hline & \multicolumn{3}{|c|}{ Group A } \\
\hline & $\begin{array}{l}\text { Before } \\
\text { PTCA }\end{array}$ & $\begin{array}{l}\text { After } \\
\text { PTCA }\end{array}$ & $p$ Value \\
\hline \multicolumn{4}{|l|}{ Frequency domain } \\
\hline Ln total power & $9.58(0.37)$ & $9.60(0.35)$ & NS \\
\hline Ln ULF power & $9.34(0.42)$ & $9.35(0.41)$ & NS \\
\hline Ln VLF power & $7.16(0.32)$ & $7.19(0.31)$ & NS \\
\hline Ln LF power & $6.10(0.23)^{*}$ & $6.36(0.28)$ & $<0.005$ \\
\hline Ln HF power & $5.36(0.40)^{*}$ & $5.70(0.39)$ & $<0.001$ \\
\hline \multicolumn{4}{|l|}{ Time Domain } \\
\hline $\operatorname{SDNN}(\mathrm{ms})$ & $88 \quad(30)$ & $94 \quad(32)$ & NS \\
\hline SDNN index (ms) & $45 \quad(14)$ & $49 \quad(15)$ & NS \\
\hline SDANN index (ms) & $70 \quad(18)^{*}$ & $83 \quad(18)$ & $<0,01$ \\
\hline \multirow[t]{3}{*}{$\mathrm{r}-\mathrm{MSSD}(\mathrm{ms})$} & $20 \quad(14)$ & $24 \quad(15)$ & NS \\
\hline & \multicolumn{3}{|c|}{ Group C } \\
\hline & $\begin{array}{c}1 \text { st } \\
\text { Recording }\end{array}$ & $\begin{array}{l}\text { 2nd } \\
\text { Recording }\end{array}$ & $p$ Value \\
\hline \multicolumn{4}{|l|}{ Frequency domain } \\
\hline Ln total power & $9.62(0.40)$ & $9.60(0.38)$ & NS \\
\hline Ln ULF power & $9.37(0.44)$ & $9.38(0.40)$ & NS \\
\hline Ln VLF power & $7.19(0.33)$ & $7.21(0.34)$ & NS \\
\hline Ln LF power & $6.37(0.26)$ & $6.36(0.28)$ & NS \\
\hline Ln HF power & $5.73(0.37)$ & $5.74(0.38)$ & NS \\
\hline \multicolumn{4}{|l|}{ Time Domain } \\
\hline $\operatorname{SDNN}(\mathrm{ms})$ & $91 \quad(30)$ & $90 \quad(30)$ & NS \\
\hline SDNN index (ms) & $46 \quad(14)$ & $45 \quad(14)$ & NS \\
\hline SDANN index (ms) & $82 \quad(19)$ & $83 \quad(20)$ & NS \\
\hline r-MSSD (ms) & $22 \quad(14)$ & $23 \quad(14)$ & NS \\
\hline
\end{tabular}

$* p<0.05$ comparing Group $\mathrm{A}$ with Groups $\mathrm{N}$ and $\mathrm{C}$. Data presented are mean value (SD). HF $=$ high frequency; $\mathrm{LF}=$ low frequency; $\mathrm{Ln}=$ natural logarithm; PTCA: percutaneous coronary angioplasty; SDANN index = standard deviation of the average normal RR intervals for all 5-minute segments; SDNN = standard deviation on all normal RR intervals; SDNN index = mean of the standard deviations of all RR intervals for all 5-minutes segments; $r$-MSSD $=$ root mean square successive difference. 
frequency power was also lower in Group A $(5.36 \pm 0.40)$ than in Group N $(5.71 \pm 0.38, p<0.01)$ and Group C $(5.73 \pm 0.37, p<0.005)$ (Table III). No difference was detectable in low and high frequency power between Groups $\mathrm{N}$ and G. Furthermore, no difference was detectable in the three groups with respect to average NN intervals and ultra low and very low frequency and total power. As to time domain measures, SDANN index (in milliseconds) was lower in Group A $(70 \pm 18)$ than in Group N $(80 \pm 18, p<0.05)$ and Group C $(82 \pm 19, p<0.05)$. No difference was detectable in SDANN index between Groups $\mathrm{N}$ and $\mathrm{G}$. There was also no difference in SDNN index and r-MSSD among the three groups. In Group $\mathrm{C}$ no change was detectable in the heart rate power spectrum between the two studies.

Correlation of heart rate variablity with summed score, coronary artery prognosis indices, ejection fraction and wall stress: No corrclation was found between any measure of heart rate variability, summed segment score, coronary artery disease prognosis index, and angiographic ejection fraction. However, there was negative association between the diastolic wall stress index and both high frequency power $(r=-0.82)$ and low frequency power $(r=-0.77)$. Similar findings were also seen in systolic wall stress index $(r=-0.72$ for high frequency power and $r=-0.64$ for low frequency power).

Effects of successful angioplasty (Tables I to IV): After coronary angioplasty no patients in Group $\mathrm{N}$ showed segmental ventricular regional wall motion abnormalities, and no change was observed in the frequency domain and timedomain measures of heart rate variability (Tables I, III and IV). In Group A the

Tahle IV. Changes in Wall Stress before and after Angioplasty (PTCA)

\begin{tabular}{|c|c|c|c|}
\hline & \multicolumn{3}{|c|}{ Group N } \\
\hline & $\begin{array}{l}\text { Before } \\
\text { PTCA }\end{array}$ & $\begin{array}{c}\text { After } \\
\text { PTCA }\end{array}$ & $p$ Value \\
\hline Diastolic wall stress $\left(\times 1000\right.$ dynes $\left./ \mathrm{cm}^{2}\right)$ & $14(5)$ & $13(5)$ & NS \\
\hline \multirow[t]{3}{*}{ Systolic wall stress $\left(\times 1000\right.$ dynes $\left./ \mathrm{cm}^{2}\right)$} & $64(18)$ & $63(19)$ & NS \\
\hline & \multicolumn{3}{|c|}{ Group A } \\
\hline & $\begin{array}{l}\text { Before } \\
\text { PTCA }\end{array}$ & $\begin{array}{l}\text { After } \\
\text { PTCA }\end{array}$ & $p$ Value \\
\hline Diastolic wall stress $\left(\times 1000\right.$ dynes $\left./ \mathrm{cm}^{2}\right)$ & $18(4)^{*}$ & $12(5)$ & $<0.01$ \\
\hline \multirow[t]{3}{*}{ Systolic wall stress $\left(\times 1000\right.$ dynes $\left./ \mathrm{cm}^{2}\right)$} & $76(20)^{*}$ & $62(18)$ & $<0.05$ \\
\hline & \multicolumn{3}{|c|}{ Group C } \\
\hline & $\begin{array}{c}1 \text { st } \\
\text { Recording }\end{array}$ & $\begin{array}{c}\text { 2nd } \\
\text { Recording }\end{array}$ & $p$ Value \\
\hline Diastolic wall stress $\left(\times 1000\right.$ dynes $\left./ \mathrm{cm}^{2}\right)$ & $12(4)$ & $12(4)$ & NS \\
\hline Systolic wall stress $\left(\times 1000\right.$ dynes $\left./ \mathrm{cm}^{2}\right)$ & $62(19)$ & $63(18)$ & NS \\
\hline
\end{tabular}

Data presented are mean (SD). 
summed segment score improved from $15.9 \pm 2.6$ to $12.2 \pm 1.7 \quad(p<0.0001)$ (Table II). There was also a significant decrease in diastolic wall stress index (in $10^{3}$ dynes $/ \mathrm{cm}^{2}$ ) (from $18 \pm 4$ to $12 \pm 5, p<0.01$ ) and in the systolic wall stress index (from $76 \pm 20$ to $62 \pm 18, p<0.05$ ) (Table IV). Mean low and high frequency power increased from $6.10 \pm 0.23$ to $6.36 \pm 0.28(p<0.005)$ and from $5.36 \pm 0.40$ to $5.70 \pm 0.39$ logarithmic units $(p<0.001)$, respectively. No difference was detectable in mean NN interval and in ultra and very low frequency and total power. Furthermore, low and high frequency power, lower at baseline in Group B, were comparable in the three groups after successful coronary angioplasty (Table III).

As to time domain measures, there was also a significant improvement in SDANN index (from $70 \pm 18$ to $83 \pm 18 \mathrm{msec}, p<0.01$ ) but not in SDNN, SDNN index and r-MSSD in Group B. No definite changes were found in any time domain measures in Groups $\mathrm{A}$ and $\mathrm{C}$.

We subdivided the Groups $\mathrm{N}$ and A into $\mathrm{Nl}(n=6), \mathrm{N} 2(n=14), \mathrm{Al}(n=10)$ and A2 $(n=12)$ where 1 means those with decreased post-angioplastic wall stress (both diastolic and systolic) and 2 means those without it. In this study, the improvements in diastolic and systolic stress are comparable $(r=0.94)$. At baseline, there were nonsignificantly lower low frequency ( $6.20 \pm 0.32$ vs. $6.34 \pm$ $0.38, p=\mathrm{NS}$ ) and high frequency powers ( $5.38 \pm 0.50 \mathrm{vs.} 5.68 \pm 0.52, p=\mathrm{NS}$ ) in Group $(\mathrm{N} 1+\mathrm{Al})$ than in Group $(\mathrm{N} 2+\mathrm{A} 2)$. After successful coronary angioplasty, low frequency power increased to $6.68 \pm 0.29(p<0.01)$ and high frequency power increased to $5.73 \pm 0.38(p<0.01)$, respectively, in Group $(\mathrm{N} 1+\mathrm{A} 1)$ while no difference existed after angioplasty in Group (N2 + A2).

\section{Discussion}

The results of this study demonstrate that in patients with coronary artery disease low and high frequency components of the heart period power spectrum are reduced only when segmental left ventricular dysfunction and/or increased left ventricular wall stress are detected. The synergistic effects of the latter two mechanisms are also observed. In fact, patients wiith coronary artery disease without regional wall motion abnormalities show heart rate variability measures comparable to those obtained in control subjects. Furthermore, the recovery in segmental dysfunction and left ventricular wall stress is associated with an improvement in heart rate variability.

Control group: The high and low frequency values that we observed in the control group are lower than those reported by Kaufman et $\mathrm{al}^{34)}$ and Goldsmith et al. ${ }^{35)}$ However, the mean ages of normal subjects in these two studies were 32 and 29 years, respectively, whereas we selected age-matched control subjects 
whose mean age was 59 years. It is well known that heart rate variability is reduced with age. ${ }^{36}$ Accordingly, Dougherty et $\mathrm{al}^{377}$ and Bonaduce et $\mathrm{al}^{13)}$ studied normal subjects with a mean age of 58 years and observed heart rate variability values similar to those we found.

Heart rate variability and extent of coronary artery disease: The relation between autonomic cardiac function and angiographic features of coronary artery disease is controversial. Rich et al $^{147}$ found no correlation between heart rate variability and number of diseased vessels. More recently Hayano et $\mathrm{al}^{15)}$ reported that coronary artery disease is associated with vagal impairment in autonomic cardiac function that correlates with the extent of coronary atherosclerosis and, to a lesser degree, with the severity of coronary stenosis. The results of our study demonstrate that there were no correlations between heart rate variability and parameters including angiographic ejection fraction, Gensini score, coronary artery disease prognosis index, and echocardiographic summed segmental score. Heart rate variability measures are reduced only when regional left ventricular dysfunction and/or increased left ventricular wall stress are detected. In fact, heart rate variability values were comparable between control subjects and patients with coronary artery disease but without left ventricular dysfunction and/ or increased wall stress.

Segmental left ventricular dysfunction and heart rate variability: The existence of reversible depression of contractility in patients with coronary artery disease has been well documented, ${ }^{38-41)}$ and two-dimensional echocardiography is a noninvasive technique capable of visualizing the improvement in segmental wall motion abnormalities after successful coronary angioplasty. ${ }^{42)}$

It has been demonstrated that an alternation in cardiac geometry secondary to the presence of a necrotic or non-contracting segment may increase discharge of sympathetic afferent fibers by mechanical distortion of their sensory endings. ${ }^{43}$; Such a sympathetic excitation interferes with tonic activity of vagal fibers directed to the sinus node. ${ }^{44,45)}$ Bonaduce et al $^{13\rangle}$ even demonstrated that alterations of cardiac geometry due to reversible segmental left ventricular dysfunction can provide a mechanism of sympathovagal imbalance in patients with one-vessel coronary disease. In this study, the lower values of low and high frequency power observed at baseline in Group A compared with Group N and C patients, and the lack of differences between the latter two groups, support the hypothesis that regional left ventricular dysfunction is involved in determining the impairment in autonomic cardiac control. However, among time measures of heart rate variability, only the SDANN index could be demonstrated to have the similar evolution in Group A as low and high frequency power spectra showed. This may indicate that the improvement of cardiac geometry secondary to successful reperfusion is stepwise or gradual and thus the improvement of heart rate vari- 
ability depends mainly on the long-term modulation of autonomic tone instead of short-term control of it. In addition, our data also indicate that segmental left ventricular dysfunction can also be a mechanism of sympathovagal imbalance in patients with multi-vessel coronary artery disease.

Wall stress and heart rate variability: Marked changes can occur in the diastolic properties and systolic contractility of the left ventricle in ischemic heart disease. Ventricular relaxation may be slowed and myocardial wall stiffness increased in the presence of acute, reversible myocardial ischemia ${ }^{45-47)}$ and myocardial infarction. ${ }^{4851)}$ Leftward displacement of the ventricular diastolic pressurevolume curve which can interfere with ventricular filling and depressed velocity of circumferential fiber shortening which reflects impaired inotropic activity may cause increases in diastolic and systolic wall stress. ${ }^{52)}$ Successful revascularization may cause adequate reperfusion and thus decrease diastolic and systolic wall stress. In our study, the improvement in heart rate variability after successful coronary angioplasty paralleled the evolution of both diastolic and systolic wall stress. The mechanoreceptors and afferent cardiac autonomic innervation may be possibly responsible for the phenomenon.

Successful coronary angioplasty and heart rate variability: After coronary angioplasty, low and high frequency power and the SDANN index increased in Group $\mathrm{A}$ and were comparable to those obtained in Groups $\mathrm{N}$ and $\mathrm{C}$. We hypothesized that the improvement in left ventricular dysfunction and wall stress after coronary angioplasty could have reduced the discharge of the sympathetic afferent fibers, restoring sympathovagal balance.

High frequency power represents a measure of the modulation of vagal tone by respiratory frequency and depth. ${ }^{27,28)}$ Thus the increase in high frequency power after coronary angioplasty reflects the recovery of parasympathetic nervous activity.

Low frequency power, measured under strictly controlled circumstances using autoregressive analysis, has been considered an indicator of sympathetic nervous system activity. ${ }^{6,12)}$ However, during 24 -hour recording it reflects predominantly parasympathetic activity. ${ }^{26,29,53)}$ Therefore, the increase in low frequency power we observed after coronary angioplasty also indicates a recovery of parasympathetic activity. Most likely, regional left ventricular dysfunction may increase afferent sympathetic activity from the heart, which in turn inhibits efferent vagal nerve activity other than inducing an increase in efferent sympathetic activity. Thus, after coronary angioplasty the improvement in regional left ventricular dysfunction could have reduced afferent sympathetic activity, which results in an improvement in Holter measures of vagal activity. The existence in the left ventricle of receptors subserved by vagal afferent fibers must also be considered; the activation of these receptors elicits cardioinhibitory vasodepressor and 
sympathoinhibitory responses. ${ }^{54)}$ In particular, the discharge pattern of ventricular receptors with unmyelinated afferents is influenced by increases in preload and afterload and by a change in cardiac contractility. ${ }^{55)}$ Therefore, the recovery of regional left ventricular function may conceivably increase the firing of these vagal afferent fibers and, as a consequence, increase the activity of vagal fibers directed to the sinus node. In addition, evolution of the SDANN index which evaluates long-term RR variations can furthermore support the finding that the improvement in heart rate variability after successful coronary angioplasty depends upon mainly the modification of parasympathetic activity instead of sympathetic tone.

The lower values of low and high frequency power and SDANN index observed at baseline in Group A also could be the consequence of reduced coronary flow. The lack of variation in heart rate variability after coronary angioplasty in patients with normal baseline echocardiographic wall motion did not support this hypothesis.

Ultralow and very low frequency power: The source of ultra low and very low frequency power is uncertain. ${ }^{11,12)}$ The lack of modification of these components of the power spectrum in our patients confirms that neural cardiac afferent activity does not contribute to their origin.

Drug therapy: No patient in this study was receiving beta-adrenergic blocker agents or angiotensin-converting enzyme inhibitors, drugs with significant effects on heart rate variability. ${ }^{53,57)}$ With respect to diltiazem, Bekheit et al ${ }^{58}$ demonstrated that in postinfarction patients this drug reduces energy in the low frequency range in the tilt position but seems to have no effect on heart rate variability when assessed by 24 -hour Holter monitoring. ${ }^{58)}$ However, it must be noted that medical treatment was the same before and after coronary angioplasty.

Study limitations: The lower values of the low and high frequency power, observed at baseline in Group A also, may be due to the higher number of patients with previous myocardial infarction in this group. In fact, in group $\mathbf{N}$ only 6 of 20 patients had a previous myocardial infarction; of these only one was anterior. This baseline difference of infarct location may be relevant because earlier data have demonstrated that anterior wall myocardial infarction results in a more profound reduction in heart rate variability than inferior infarct location. ${ }^{59)}$ However, it must be borne in mind that after coronary angioplasty the power spectrum was comparable in the two groups, despite the differences in infarct location.

Ejection fraction was lower in Group A patients. In agreement with earlier reports, we found no correlation between frequency domain measures and ejection fraction. Nevertheless, this variable could have influenced the results we 
observed. In addition, assessment of angiographic ejection fraction after coronary angioplasty could be useful in clarifying the relative roles of global and regional left ventricular dysfunction.

Finally, to better define the mechanisms underlying recovery of heart rate variability after coronary angioplasty it would be useful to evaluate a group of patients with achieved patency of coronary vessel without improvement in wall motion and/or wall stress. However, in our study patients the success of coronary angioplasty was always followed by recovery of wall motion and wall stress.

Conclusions: The results of this study offer new insights into the mechanism underlying the reduction of heart rate variability in patients with coronary artery disease and demonstrate that regional left ventricular dysfunction and increased left ventricular wall stress are involved in determining sympathovagal imbalance in these patients. The recovery of segmental dysfunction after coronary angioplasty is associated with an improvement in autonomic cardiac control of heart rate.

\section{REFERENCES}

1. Thames MD, Klopfenstein HS, Abbound FM, et al. Preferential distribution of inhibitory cardiac receptors with vagal afferents to the inferoposterior wall of the left ventricle activated during coronary occlusion in the dog. Circ Res 1981; 43: 685-92.

2. Webb SW, Adrey AA, Pantridge JF. Autonomic disturbance at onset of acute myocardial infarction. Br Med J 1972; 3: 89-92.

3. Malliani A, Schwartz PJ, Zanchetti A. Sympathetic reflex elicited by experimental coronary occlusion. Am J Physiol 1969; 217: 703-9.

4. Uchida Y, Kamisaka K, Murao S, et al. Mechanosensitivity of afferent cardiac parasympathetic nerves. Am J Physiol 1974; 225: 1088-93.

5. Bigger JT Jr, Kleiger RE, Fleiss JL, Rolnitzky LM, Steinman RC, Miller JP, and the Multicenter PostInfarction Research Group. Components of heart rate variability measured during healing of acute myocardial infarction. Am J Cardiol 1988; 61: 208-15.

6. Lombardi F, Sandrone $G$, Pernpruner $S$. Heart rate variability as an index of sympathovagal interaction after acute myocardial infarction. Am J Cardiol 1987; 60: 1239-45.

7. Schwartz PJ, Zaza A, Pala M, et al. Baroreflex sensitivity and its evolution during the first year after myocardial infarction. J Am Coll Cardiol 1988; 12: 629-36.

8. Osculati G, Grassi G, Giannattasio C. Early alternations of the baroreceptor control of heart rate in patients with acute myocardial infarction. Circulation 1990; 81: 939-48.

9. La Rovere MT, Specchia G, Mortara A, et al. Baroreflex sensitivity, clinical correlates, and cardiovascular mortality among patients with a first myocardial infarction: a prospective study. Circulation 1988; 78: $816-24$.

10. Kleiger RE, Miller JP, Bigger JT Jr, Moss AJ, and the Multicenter Post-Infarction Research Group. Decreased heart rate variability and its association with increased mortality after acute myocardial infarction. Am J Cardiol 1987; 59: 256-62.

11. Bigger JT Jr, Fleiss JL, Steinman RC, et al. Frequency domain measures of heart period variability and mortality after myocardial infarction. Circulation 1992; 85: 164-71.

12. Bigger JT Jr, Hoover CA, Steinman RC, Rolnitzky LM, Fleiss JL, and The Multicenter Study of Silent Myocardial Ischemia Investigators. Autonomic nervous system activity during myocardial ischemia in man estimated by power spectral analysis of heart period variability. Am J Cardiol 1990; 66: 497-8.

13. Bonaduce D, Petretta $\mathrm{M}$, Piscione $\mathrm{F}$, et al. Influence of reversible segmental left ventricular dysfunc- 
tion on heart period variability in patients with one-vessel coronary artery disease. J Am Coll Cardiol 1994; 24: 399-405.

14. Rich MW, Saini JS, Kleiger RE, et al. Correlation of heart rate variability with clinical and angiographic variables and late mortality after coronary angiography. Am J Cardiol 1988; 62: 714-7.

15. Hayano J, Yamada A, Mukai S. Severity of coronary atherosclerosis correlates with the respiratory component of heart rate variability. Am Heart J 1991; 121: 1070-9.

16. Hayano J, Sakakibara Y, Yamada M. Decreased magnitude of heart rate spectral components in coronary artery disease. Its relation to angiographic severity. Circulation 1990; 81: 1217-24.

17. Edwards WD, Tajik AJ, Seward JB. Standardized nomenclature and anatomic basis for regional tomographic analysis of the heart. Mayo Clin Proc 1981; 56: 479-98.

18. Stratton JR, Speck SM, Caldwell JH. Late effects of intracoronary streptokinase on regional wall motion, ventricular aneurysm and left ventricular thrombus in myocardial infarction: results from Western Washington randomized trial. J Am Coll Cardiol 1985; 5: 1023-8.

19. Reichek N, Wilson J, Sutton MS, et al. Noninvasive determination of left ventricular end-systolic stress: validation of the method and initial application. Circulation 1982; 65: 297-303.

20. Bruce RA, Fisher LD. Exercise-enhanced assessment of risk factors for coronary heart disease in healthy men. J Electrocardiol 1987; (Suppl October): 162-8.

21. DeBoer RW, Karemaker JM, Strackee J. Comparing spectra of a series of point events particularly for heart rate variability data. IEEE Trans Biomed Eng 1984; 31: 384-7.

22. Berger RD, Akselrod S, Gordon D, et al. An efficient algorithm for spectral analysis of heart rate variability. IEEE Trans Biomed Eng 1986; 33: 900-4.

23. Marciano F, Mazzarella M, Migaux ML. Performance evaluation of a Holter recording computer analysis system. Comput Cardiol 1981; 8: 523-6.

24. Marciano F, Mazzarella M, Migaux ML. A signal processor system for the analysis of EEG and ECG recordings. Proceedings ISMM symposium: Microcomputer Applications in Medline and Bioengineering. Anaheim (CA): Acta Press, 1985: 10-4.

25. Bigger JT Jr, Fleiss JL, Rolnitzky LM, et al. Time course of recovery of heart period variability after myocardial infarction. J Am Coll Cardiol 1991; 18: 1643-9.

26. Pagani M, Lombardi F, Guzzetti S, et al. Power spectral analysis of heart rate and arterial pressure variabilities as a marker of sympathovagal interactions in man and conscious dogs. Circ Res 1986; 59: 178-93.

27. Pomeranz B, Macaulay RJB, Gaudill MA, et al. Assessment of autonomic function in humans by heart rate spectral analysis. Am J Physiol 1985; 248: H151-H153.

28. Koizumi $\mathrm{K}$, Terui N, Kollai M. Effect of cardiac vagal and sympathetic nerve activity on heart rate in rhythmic regulation. J Auton Nerv Syst 1985; 12: 251-9.

29. von Neumann J, Kent RH, Bellinson HR, et al. The mean square successive difference. Ann Math Stat 1941; 12: 153-62.

30. Pepine CJ, Hill JA, Lambert CR. Catheterization and radiographic techniques. In: Pepine CJ et al editors. Diagnostic and Therapeutic Cardiac Catheterization. Williams \& Wilkins 1989: 67-201.

31. Sandler $\mathrm{H}$, Dodge HT. The use of single-plane angiocardiograms for the calculation of lcft vcntricular volume in man. Am Heart J 1968; 75: 325-34.

32. Gensini GG. A more meaningful scoring system for determining the severity of coronary heart disease. Am J Cardiol 1983; 51: 606.

33. Austin WG, Edwards JE, Frye RL, et al. A reporting system on patients evaluated for coronary artery disease, Council on Cardiovascular Surgery, American Heart Association. Circulation 1975; 51 (Suppl 4): 30 .

34. Kaufman ES, Bosner MS, Bigger JT Jr. Effects of digoxin and enalapril on heart period variability and response to head-up tilt in normal subjects. Am J Cardiol 1993; 72: 95-9.

35. Goldsmith RL, Bigger JT Jr, Steinman RC, et al. Comparison of 24-hour parasympathetic activity in endurance-trained and untrained young men. J Am Coll Cardiol 1992; 20: 552-8.

36. Lipsitz LA, Mietus J, Moody GB, et al. Spectral characteristics of heart rate variability before and during postural tilt: relations to aging and risk of syncope. Circulation 1990; 81: 1803-10.

37. Dougherty CM, Burr RL. Comparison of heart rate variability in survivors and nonsurvivors of 
sudden cardiac arrest. Am J Cardiol 1992; 70: 441-8.

38. Braunwald E, Rutherford JD. Reversible ischemic left ventricular dysfunction: cvidence for the "herbinating myocardium". J Am Coll Cardiol 1986; 8; 1467-70.

39. Brundage GH, Massie BM, Botvinick EH. Improved regional ventricular function after successful surgical revascularization. J Am Coll Cardiol 1984; 3: 902-8.

40. Ross J Jr. Myocardial perfusion-contraction matching: implications for coronary heart disease and hibernation. Circulation 1991; 83: 1076-83.

41. Bolli R. Myocardial "stunning" in man. Circulation 1992; 86: 1671-91.

42. van den Berg EK Jr, Popma J, Dehemer GJ. Reversible segmental left ventricular dysfunction after coronary angioplasty. Circulation 1990; 81: 1210-6.

43. Malliani A, Recordati G, Schwartz PJ. Nervous activity of afferent cardiac sympathetic fibers with atrial and ventricular endings. J Physiol (London) 1973; 229: 457-69.

44. Schwartz PJ, Pagani M, Lombardi F, et al. A cardiocardiac sympathovagal reflex in the cat. Circ Res 1973; 32: 215 20.

45. Vatner SF, Shannon R, Hittinger L. Reduced subendocardial coronary reserve: A potential mechanism for impaired diastolic function in the hypertrophied and failing heart. Circulation 1990; 81 (Suppl II): $1118-14$

46. Serizawa T, Carabello BA, Grossman W. Effect of pacing-induced ischemia on left ventricular diastolic pressure-volume relations in dogs with coronary stenosis. Circ Res 1980; 46: 430-7.

47. Hess OM, Osakada G, Lavelle JF, et al. Diastolic myocardial wall stiffness and ventricular relaxation during partial and complete coronary occlusions in conscious dogs. Circ Res 1983; 52: 387-400.

48. Forrester J, Diamond C, Parmley WW, et al. Early increase in left ventricular compliance following myocardial infarction. J Clin Invest 1972; 51: 598-604.

49. Pirzada FA, Ekong EA, Vokonas PS. Experimental myocardial infarction. XIII. Sequential changes in left ventricular pressure-length relations in the acute phase. Circulation 1976; 53: 970-8.

50. Swan HJC, Forrester JS, Diamond G, et al. Hemodynamic spectrum of myocardial infarction and cardiogenic shock. Circulation 1972; 40: 1097-110.

51. Farhi ER, Canty J, Klocke FJ. Effects of graded reductions in coronary perfusion pressure on the diastolic pressure-segment length relation and the rate of isovolumic relaxation in the resulting conscious dog. Circulation 1972; 45: 11-20.

52. Grossman W, Jones D, McLaurin LP. Wall stress and patterns of hypertrophy in the human left ventricle. J Glin Invest 1975; 56: 56-64.

53. Cook JR, Bigger JT Jr, Kleiger RE, et al. Effect of atenolol and diltiazem on heart period variability in normal persons. J Am Coll Cardiol 1991; 17: 480-4.

54. Mark AL. The Bezold-Jarish reflex revisited: clinical implications of inhibitory reflexes originating in the heart. J Am Coll Cardiol 1983; 1: 90-102.

55. Thoren P. Characteristics of left ventricular receptors with non-modulated vagal afferents in cats. Girc Res 1977; 40: 415-21.

56. Sayers B. Analysis of heart rate variability. Ergonomics 1973; 16: 17-32.

57. Akselrod S, Gordon D, Ubel FA, et al. Power spectrum analysis of heart rate fluctuation: a quantitative probe of beat-to-beat cardiovascular control. Science 1981; 213: 220-2.

58. Bekeit $\mathrm{S}$, Tangella $\mathrm{M}$, el-Sakr A, et al. Use of heart rate spectral analysis to study the effects of calcium channel blockers on sympathetic activity after myocardial infarction. Am Heart J 1990; 119: 7985.

59. Pipilis A, Flather M, Ormerod $O$, et al. Heart rate variability in acute myocardial infarction and its association with infarct site and clinical course. Am J Cardiol 1991;67: 1137-9. 